\title{
Níveis de Bagaço de Cana e Uréia como Substituto ao Farelo de Soja em Dietas para Bovinos Leiteiros em Crescimento 1
}

\section{Luciana Brandão Torres², Marcelo de Andrade Ferreira3,4, Antonia Sherlânea Chaves Véras ${ }^{3}$, Airon Aparecido Silva de Melo ${ }^{5}$, Dulciene Karla Bezerra de Andrade ${ }^{5}$}

\begin{abstract}
RESUMO - Com o objetivo de avaliar diferentes níveis de bagaço e uréia como substituto ao farelo de soja em dietas para bovinos leiteiros em crescimento, dois experimentos foram realizados. No primeiro, 20 bezerros mestiços Holandês x Zebu foram distribuídos em quatro tratamentos em delineamento inteiramente casualizado. Os animais receberam dietas à base de palma forrageira e bagaço de cana em níveis de 5,5;14,4;24,4 e 34\% da matéria seca total. O ganho de peso diminuiu, enquanto a conversão alimentar, e os consumos de FDN e FDA aumentaram linearmente com a inclusão de bagaço. O consumo máximo de MS foi estimado em 2,73\% do peso vivo com $30 \%$ de bagaço de cana. No segundo experimento foi avaliada a substituição do farelo de soja (FS) por uréia mais milho moído (UM), em dietas à base de palma forrageira, sobre o desempenho de novilhas mestiças Holandês x Zebu. Vinte animais foram alimentados de acordo com os níveis de substituição do FS por UM (0, 20, 40 e 60\%) distribuídos em blocos ao acaso. Não houve efeito da substituição parcial do farelo de soja por milho e uréia sobre o desempenho de novilhas mestiças.
\end{abstract}

Palavras-chave: consumo de alimentos, conversão alimentar, ganho de peso, palma forrageira

\section{Sugar Cane Bagasse and Urea as Replacement of Soybean Meal in the Growing Dairy Cattle Diets}

\begin{abstract}
In order to evaluate different levels of sugar cane bagasse and urea as replacement of soybean meal in growing dairy cattle diets, two trials were conducted. In the first, twenty crossbreed bull calves (Holstein x Zebu) were allotted in a completely randomized design with four treatments. The animals were fed forage cactus based diets, containing levels of 5.5, 14.4, 24.4 and 34\% of sugar cane bagasse on the dry matter basis. The liveweight gain decreased while the feed: gain ratio, FDN and FDA intakes increased linearly in function of the increased level of sugar cane bagasse. The maximum daily dry matter intake of $2.73 \%$ of LW was estimated with $30 \%$ of sugar cane bagasse in the diet. In the second, was evaluated the partial replacement of soybean meal (SM) by urea plus corn cracked (UC) in forage cactus based diets on the crossbreed (Holstein x Zebu) heifers performance. Twenty animals were fed diets containing four levels $(0,20,40$ and $60 \%)$ of replacement of SM by UC. There was no significant effect of partial replacement of soybean meal by urea plus corn cracked on crossbreed heifers performance.
\end{abstract}

Key Words: intake, feed:gain ratio, average daily gain, forage cactus

\section{Introdução}

O complexo agro-industrial do estado de Pernambuco é diversificado apresentando diferenças entre as distintas regiões fisiográficas e sóciopolíticas. Neste contexto, destacam-se quatro principais cadeias agro-industriais, a saber: cana-de-açúcar, avicultura, agricultura irrigada e leite representam $80 \%$ do PIB agropecuário. Em todas as regiões do estado, e em especial na região semi-árida, a exploração pecuária se constitui em uma das principais alternativas econômicas.

O Agreste Pernambucano responde por cerca de
$60 \%$ da produção de leite de todo estado. Esta região é caracterizada por baixa precipitação pluviométrica durante o ano e vem experimentando seguidas secas nos últimos anos. $\mathrm{O}$ desempenho do rebanho leiteiro deixa a desejar e pode ser traduzido pela baixa produção de leite/vaca/ano, longos intervalos de partos, idade avançada ao primeiro parto, altas taxas de mortalidade e morbidade de animais jovens, dentre outros.

Nos últimos anos foi notável a utilização de tecnologias de produção de espécies adaptadas a estresse hídrico, com destaque para a palma forrageira. Estima-se que existam mais de 100.000 ha plantados com esta cactácea, sendo este um fator

\footnotetext{
1 Trabalho parcialmente financiado pela FACEPE.

2 Aluna do curso de Medicina Veterinária da UFRPE - Bolsista PIBIC /CNPq-UFRPE.

3 Professor do Departamento de Zootecnia da UFRPE.

4 Pesquisador do CNPq. E.mail: ferreira@ufrpe.br

5 Aluno do programa de Pós-Graduação em Zootecnia da UFRPE.
} 
determinante para que o rebanho leiteiro não sofresse redução acentuada nas secas de 1992-93 e 1997-99. Apesar de sua importância e da disponibilidade de tecnologias para sua produção não existem, na literatura, trabalhos sobre a utilização da palma forrageira como recurso alimentar para as diferentes categorias do rebanho leiteiro.

Essa forragem apresenta baixos teores de matéria seca, fibra, proteína bruta e fósforo e altos teores de cálcio e carboidratos solúveis. Sua utilização como volumoso exclusivo para bovinos de leite tem resultado em baixas produções de leite, queda no teor de gordura do leite, baixos consumos de matéria seca, perda de peso dos animais e constantes diarréias (Santos et al., 1997).

Nível adequado de fibra se faz necessário na ração de ruminantes para o normal funcionamento do rúmen (Mertens, 1992).

O bagaço de cana é resultante da extração do caldo da cana-de-açúcar e é caracterizado como um alimento com altos teores de parede celular, baixa densidade energética e pobre em proteína e minerais, constituindose em um volumoso de baixo valor nutritivo e de baixo potencial de uso na alimentação animal (Nussio \& Balsalobre, 1993). Por outro lado, o bagaço poderia ser incluído em rações à base de palma forrageira para ruminantes, principalmente para corrigir a deficiência em fibra e os distúrbios verificados em animais alimentados exclusivamente com essa cactácea.

Várias fontes de proteína estão disponíveis no mercado, destacando-se o farelo de soja, um dos principais alimentos protéicos disponíveis para a alimentação de bovinos, com excelente composição e sem restrição de uso (Campos et al., 1995). Porém um dos principais entraves na utilização do farelo de soja é o alto preço, implicando em aumento no custo de produção. Por outro lado, a uréia é uma fonte de nitrogênio não protéico, largamente utilizada na alimentação de ruminantes. A grande vantagem de sua utilização advém do fato de que o ruminante, através dos microrganismos do rúmen, pode satisfazer suas exigências em proteína a partir do nitrogênio não protéico, quando o nível de produção é moderado.

A palma apresenta alto teor de carboidratos solúveis, o que facilitaria a utilização de uréia, contribuindo para diminuir os custos com outra fonte protéica. Desta forma, a uréia é uma importante alternativa para o farelo de soja, representando vantagem econômica, devido a redução do gasto com fontes de proteína verdadeira.
As informações na literatura sobre a utilização da palma forrageira em dietas de bovinos em crescimento ainda são bastante escassas. Os objetivos deste trabalho foram estudar os efeitos de diferentes níveis de bagaço de cana e a substituição do farelo de soja por uréia mais milho em rações à base de palma forrageira, sobre o desempenho de bovinos mestiços de origem leiteira, em crescimento.

\section{Material e Métodos}

Experimento 1. $\mathrm{O}$ experimento foi realizado na Fazenda Laje, no município de Cahoeirinha, que se localiza no Agreste Meridional do Estado de Pernambuco, distante cerca de $180 \mathrm{~km}$ da cidade de Recife.

Foram utilizados 20 bezerros mestiços (3/4 Holandês x Zebu), não castrados, com idade de 12 meses e peso vivo médio inicial de $160 \mathrm{~kg}$, alojados em baias individuais. As baias eram de chão batido, separadas por arame farpado e com dimensões de 2 × 2 metros e dotadas de cocho para alimentação e bebedouro.

Os animais, após controle de ecto e endoparasitas, passaram por um período de 30 dias de adaptação ao manejo experimental e às instalações. Todos os bezerros, após jejum de sólidos de 16 horas, foram pesados no início do período de comparação, a cada 28 dias e no final do período experimental, que foi de 84 dias.

Os animais foram alimentados à vontade, duas vezes ao dia (às 8 e 16 h), ajustando-se um percentual de sobra diária de 5 a $10 \%$, como forma de manter os níveis dos ingredientes das rações. O bagaço utilizado foi adquirido de usinas e armazenado em local seco e arejado. A cultivar de palma utilizada foi a Gigante. A cama de frango foi adquirida de granjas da própria região. A palma foi fornecida na forma picada misturada ao bagaço, cama de frango e farelo de trigo, no próprio cocho. A composição percentual dos ingredientes das dietas experimentais é apresentada na Tabela 1 e a composição bromatológica, na Tabela 2 . $\mathrm{O}$ alimento fornecido, bem como as sobras, foi pesado diária e individualmente. Amostras dos ingredientes das rações foram coletadas semanalmente.

Os tratamentos experimentais consistiram de diferentes níveis de bagaço na ração: 5,$5 ; 14,4$; 24,4 ; e $34,0 \%$. As proporções calculadas foram de $5,15,25$ e $35 \%$, mas, devido às constantes mudanças nos teores de matéria seca dos ingredientes, foi impossível manter esta relação durante todo o experimento. Todos os animais, independentemente dos 
Tabela 1 - Composição percentual dos ingredientes nos tratamentos experimentais com base na matéria seca

Table 1 - Composition (\%) of the experimental diets on dry matter basis

\begin{tabular}{lcccc}
\hline $\begin{array}{l}\text { Ingrediente } \\
\text { Ingredient }\end{array}$ & \multicolumn{5}{c}{$\begin{array}{c}\text { Níveis de bagaço (\%) } \\
\text { Sugar cane bagasse levels (\%) }\end{array}$} \\
\cline { 2 - 5 } & 5,5 & 14,4 & 24,4 & 35,0 \\
\hline $\begin{array}{l}\text { Palma forrageira } \\
\text { Forage cactus }\end{array}$ & 50,0 & 41,1 & 31,1 & 20,5 \\
$\begin{array}{l}\text { Bagaço de cana } \\
\text { Sugar cane bagasse }\end{array}$ & 5,5 & 14,4 & 24,4 & 35,0 \\
$\begin{array}{l}\text { Farelo de trigo } \\
\text { Wheat bran }\end{array}$ & 22,25 & 22,25 & 22,25 & 22,25 \\
$\begin{array}{l}\text { Cama de frango } \\
\text { Poultry litter }\end{array}$ & 22,25 & 22,25 & 22,25 & 22,25 \\
\hline
\end{tabular}

Tabela 2 - Teores médios de matéria seca (MS), matéria orgânica (MO) proteína bruta (PB), fibra em detergente neutro (FDN) e fibra em detergente ácido (FDA) das dietas experimentais

Table 2 - Average contents of dry matter (DM), organic matter $(O M)$, crude protein $(C P)$, neutral detergent fiber (NDF) and acid detergent fiber (ADF) of the experimental diets

\begin{tabular}{lllll}
\hline \multirow{2}{*}{$\begin{array}{l}\text { Nutriente } \\
\text { Nutrient }\end{array}$} & \multicolumn{4}{c}{$\begin{array}{c}\text { Níveis de bagaço (\%) } \\
\text { Sugar cane bagasse levels (\%) }\end{array}$} \\
\cline { 2 - 5 } & 5,5 & 14,4 & 24,4 & 35,0 \\
\hline MS (DM) & 47,16 & 51,76 & 57,25 & 65,01 \\
MO $^{1}(O M)$ & 91,46 & 92,11 & 92,84 & 93,47 \\
PB $^{1}(C P)$ & 11,3 & 11,2 & 11,1 & 11,0 \\
FDN $^{1}(N D F)$ & 36,5 & 41,61 & 47,7 & 53,6 \\
FDA $^{1}($ ADF $)$ & 13,15 & 15,46 & 18,08 & 20,50 \\
\hline
\end{tabular}

$1 \%$ na MS (\% of DM).
Experimento 2. Foram utilizadas 20 novilhas mestiças (3/4 HZ), com idade média de 15 meses e peso médio inicial de $185 \mathrm{~kg}$. O local, o manejo dos animais, a coleta de amostras e os parâmetros avaliados foram os mesmos adotados para o experimento 1 .

Os tratamentos foram constituídos de diferentes níveis de substituição do farelo de soja pela mistura milho mais uréia, com níveis constantes de palma forrageira e bagaço de cana. $\mathrm{O}$ delineamento experimental foi o de blocos casualizados, tendo como critério o peso inicial das novilhas.

A composição percentual dos ingredientes das dietas experimentais é apresentada na Tabela 3 e a composição bromatológica, na Tabela 4.

Tabela 3 - Composição percentual dos ingredientes nos tratamentos experimentais com base na matéria seca

Table 3 - Composition (\%) of the experimental diets on dry matter basis

\begin{tabular}{lcccc}
\hline $\begin{array}{l}\text { Ingrediente } \\
\text { Ingredient }\end{array}$ & \multicolumn{4}{c}{$\begin{array}{c}\text { Níveis de substituição (\%) } \\
\text { Replacement levels (\%) }\end{array}$} \\
\cline { 2 - 5 } & 0 & 20 & 40 & 60 \\
\hline $\begin{array}{l}\text { Palma forrageira } \\
\text { Forage cactus }\end{array}$ & 50,0 & 50,0 & 50,0 & 50,0 \\
$\begin{array}{l}\text { Bagaço de cana } \\
\text { Sugar cane bagasse }\end{array}$ & 30,0 & 30,0 & 30,0 & 30,0 \\
$\begin{array}{l}\text { Milho moído } \\
\text { Cracked corn }\end{array}$ & 0,0 & 3,4 & 6,8 & 10,2 \\
$\begin{array}{l}\text { Farelo de soja } \\
\text { Soybean meal }\end{array}$ & 20,0 & 16,0 & 12,0 & 8,0 \\
$\begin{array}{l}\text { Uréia } \\
\text { Urea }\end{array}$ & 0,0 & 0,6 & 1,2 & 1,8 \\
\hline
\end{tabular}

Tabela 4 - Teores médios de matéria seca (MS), matéria orgânica (MO) proteína bruta (PB), fibra em detergente neutro (FDN) e fibra em detergente ácido (FDA) das dietas experimentais

Table 4 - Average contents of dry matter (DM), organic matter $(O M)$, crude protein (CP), neutral detergent fiber (NDF) and acid detergent fiber (ADF) of the experimental diets

\begin{tabular}{lcccl}
\hline $\begin{array}{l}\text { Nutriente } \\
\text { Nutrient }\end{array}$ & \multicolumn{4}{c}{$\begin{array}{c}\text { Níveis de substituição (\%) } \\
\text { Replacement levels (\%) }\end{array}$} \\
\cline { 2 - 5 } & 0 & 20 & 40 & 60 \\
MS (\%) (DM \%) & 43,4 & 43,6 & 43,8 & 44,0 \\
OO $^{1}(O M)$ & 92,5 & 92,3 & 91,9 & 91,6 \\
$\operatorname{PB}^{1}(C P)$ & 12,94 & 12,99 & 12,98 & 13,03 \\
$\mathrm{FDN}^{1}(N D F)$ & 41,0 & 41,1 & 41,1 & 41,3 \\
FDA $^{1}($ (ADF) & 24,72 & 24,41 & 24,1 & 23,80 \\
\hline
\end{tabular}

$1 \%$ na MS (\% of $D M)$. 


\section{Resultados e Discussão}

Experimento 1. Os resultados referentes ao ganho de peso, em kg/dia, (GP) conversão alimentar (CA) e consumos de matéria seca (MS), matéria orgânica (MO), fibra em detergente neutro (FDN), fibra em detergente ácido (FDA) e proteína bruta (PB), em função dos níveis de bagaço na ração são apresentados na Tabela 5 .

Houve efeito quadrático $(\mathrm{P}<0,01)$ para consumo de MS (kg/dia e \%PV), sendo o máximo estimado em $5,62 \mathrm{~kg} /$ dia e $2,73 \% \mathrm{PV}$, com $30 \%$ de bagaço na dieta. Pode-se verificar pela Tabela 5 que houve aumento no consumo de MS até o nível de 24,4\% ocorrendo, a partir daí, queda no consumo. Como sugerido por Oliveira (1996), a inclusão de um ingrediente mais fibroso e com maior teor de MS às rações, provocou aumento no consumo de MS, até certo ponto. Com a inclusão do bagaço ocorreu também aumento no teor de fibra (Tabela 2) e, conseqüentemente, no volume total da ração. O consumo voluntário de MS está relacionado com o conteúdo de fibra na ração, por alterar os padrões de fermentação e a velocidade passagem da fibra pelo trato gastrintestinal. Isto provoca um grande efeito de enchimento do trato gastrintestinal, alongando o tempo de permanência do alimento no rúmen. Quando o volume da ração é o fator limitante, os animais são incapazes de ingerir quantidades suficientes de nutrientes para suprir as necessidades energéticas, o que implica em menor produção (Signoretti et al. 1999a).

Comportamento semelhante para o consumo de MS foi verificado por Carvalho et al.(1997), Tibo et al. (1997) e Araújo et al.(1998), trabalhando com níveis crescentes de volumoso e, conseqüentemente de fibra, em dietas para bovinos.

O consumo de MO, tanto em $\mathrm{kg} / \mathrm{dia}$, quanto \% PV, comportou-se de maneira similar ao consumo de MS e a ingestão máxima foi estimada em $4,97 \mathrm{~kg} / \mathrm{dia}$ e $2,56 \%$ PV, para os níveis de 27,5 e 30\% de bagaço na ração, respectivamente.

Os consumos de FDN e FDA, em kg/dia e \% do $\mathrm{PV}$, aumentaram linearmente $(\mathrm{P}<0,01)$ com o aumento do teor de bagaço nas rações. Com a inclusão

Tabela 5 - Consumos médios diários de matéria seca (CMS), matéria orgânica (CMO), fibra em detergente neutro (CFDN), fibra em detergente ácido (CFDA), proteína bruta (CPB); ganho de peso (GP) e conversão alimentar (CA) de bezerros mestiços confinados

Table 5 - Average daily intake of dry matter(DMI), organic matter (OMI), neutral detergent fiber (NDFI), acid detergent fiber (ADFI), crude protein (CPI); average daily gain (ADG) and feed:gain ratio (FGR) of feedlot crossbreed bul calves

\begin{tabular}{|c|c|c|c|c|c|c|}
\hline \multirow[t]{2}{*}{$\begin{array}{l}\text { Item } \\
\text { Item }\end{array}$} & \multicolumn{4}{|c|}{$\begin{array}{l}\text { Níveis de substituição (\%) } \\
\text { Replacement levels (\%) }\end{array}$} & \multirow[t]{2}{*}{$\begin{array}{l}\text { Equações de regressão } \\
\text { Regression equations }\end{array}$} & \multirow[t]{2}{*}{$\mathrm{r}^{2} / \mathrm{R}^{2}$} \\
\hline & 5,5 & 14,4 & 24,4 & 35,0 & & \\
\hline $\begin{array}{l}\text { CMS (kg/dia) } \\
\text { DMI (kg/day) }\end{array}$ & 4,46 & 4,86 & 5,60 & 5,31 & $\mathrm{Y}=3,82+0,12^{* *} \mathrm{~B}-0,002^{* *} \mathrm{~B}^{2}$ & 0,89 \\
\hline $\begin{array}{l}\text { CMS (\% PV) } \\
D M I(\% L W)\end{array}$ & 2,15 & 2,40 & 2,72 & 2,62 & $\mathrm{Y}=1,83+0,06 * * \mathrm{~B}-0,001 * * \mathrm{~B}^{2}$ & 0,95 \\
\hline $\begin{array}{l}\text { CMO (kg/dia) } \\
\text { OMI (kg/day) }\end{array}$ & 4,07 & 4,48 & 5,19 & 4,96 & $\mathrm{Y}=3,46+0,11 * * \mathrm{~B}-0,002 * * \mathrm{~B}^{2}$ & 0,91 \\
\hline $\begin{array}{l}\text { CMO }(\% \mathrm{PV}) \\
O M I(\% L W)\end{array}$ & 1,96 & 2,20 & 2,52 & 2,45 & $\mathrm{Y}=1,66+0,06 * * \mathrm{~B}-0,001 \mathrm{~B}^{2}$ & 0,95 \\
\hline $\begin{array}{l}\text { CFDN (kg/dia) } \\
N D F I(k g / \text { day })\end{array}$ & 1,47 & 1,82 & 2,40 & 2,56 & $\mathrm{Y}=1,27+0,0403 * * \mathrm{~B}$ & 0,96 \\
\hline $\begin{array}{l}\text { CFDN (\%PV) } \\
\text { NDFI (kg/day) }\end{array}$ & 0,71 & 0,90 & 1,17 & 1,26 & $\mathrm{Y}=0,62+0,0201 * * \mathrm{~B}$ & 0,97 \\
\hline $\begin{array}{l}\text { CFDA (kg/dia) } \\
A D F I \text { (kg/day) }\end{array}$ & 0,58 & 0,74 & 0,99 & 1,01 & $\mathrm{Y}=0,52+0,02 * * \mathrm{~B}$ & 0,92 \\
\hline $\begin{array}{l}\text { CFDA (\%PV) } \\
A D F I(\% L W)\end{array}$ & 0,28 & 0,37 & 0,48 & 0,50 & $\mathrm{Y}=0,25+0,01 * * \mathrm{~B}$ & 0,94 \\
\hline $\begin{array}{l}\text { CPB (kg/dia) } \\
\text { CPI (kg/day) }\end{array}$ & 0,58 & 0,53 & 0,60 & 0,56 & $Y=0,57$ & - \\
\hline $\begin{array}{l}\mathrm{GP} \mathrm{kg} / \mathrm{dia}) \\
A D G(\mathrm{~kg} / \text { day })\end{array}$ & 0,84 & 0,77 & 0,74 & 0,61 & $\mathrm{Y}=0,89-0,008^{* *} \mathrm{~B}$ & 0,93 \\
\hline $\begin{array}{l}\mathrm{CA}(\mathrm{kg} \mathrm{MS} / \mathrm{kg} \mathrm{GP}) \\
\text { DMI:ADG ratio }\end{array}$ & 5,31 & 6,31 & 7,57 & 8,70 & $\mathrm{Y}=4,63+0,12 * * \mathrm{~B}$ & 0,99 \\
\hline
\end{tabular}

$\mathrm{B}=$ Nível de bagasso $(B=\text { sugar cane bagasse level })^{* *}=$ significativo a $1 \%$ de probabilidade pelo teste $\mathrm{t}\left({ }^{* \star}\right.$ Significant at $P<0$. by $t$ test $)$. 
do bagaço houve aumento do teor destes componentes nas dietas e, consequientemente, um aumento no consumo, mesmo para o teor de $30 \%$ onde ocorreu queda no consumo de MS.

Apesar de ter havido aumento no consumo até certo nível, este não foi capaz de minimizar a queda linear ocorrida no ganho de peso, com consequiente aumento linear $(\mathrm{P}<0,01)$ na conversão alimentar. Este comportamento pode ser explicado, parcialmente, pela substituição da palma forrageira, um alimento com baixo teor de fibra, alta concentração de carboidratos solúveis e elevado coeficiente de digestibilidade (Santos et al., 1997), pelo bagaço de cana in natura, um alimento com grande concentração de fibra e de baixa digestibilidade (Nussio \& Balsalobre, 1993). Como conseqüência, houve aumento linear no teor de FDA das rações com a inclusão do bagaço de cana $\left(=11,74+0,26 \mathrm{~B}, \mathrm{r}^{2}=\right.$ 0,99 , em que $\mathrm{B}=$ nível de bagaço). Weiss (1998) citou várias análises de regressão que utilizam a concen- tração de FDA para estimar a energia líquida dos alimentos, que diminui com o aumento do teor de FDA. A adição de bagaço diminuiu a concentração energética das dietas, proporcionando menor consumo de energia e menor ganho de peso, mesmo com aumento no consumo de matéria seca. Por outro lado, os níveis de bagaço de cana não afetaram $(\mathrm{P}>0,05) \mathrm{o}$ consumo de PB.

Comportamento semelhante ao do presente estudo foi verificado por Bartle et al. (1994), Ferreira (1997) e Signoretti et al. (1999b) que também observaram decréscimo linear no ganho de peso com a inclusão de material fibroso na dieta de bovinos.

Vale ressaltar que os animais que receberam a dieta com 5,5\% de bagaço de cana apresentaram repetidas diarréias, o que não ocorreu com os demais tratamentos. Santana et al 1972, trabalhando com dietas à base de palma forrageira para vacas em lactação, também verificaram diarréia intensa além de perda de peso dos animais.

Tabela 6 - Consumos médios diários de matéria seca (CMS), matéria orgânica (CMO), fibra em detergente neutro (CFDN), fibra em detergente ácido (CFDA), proteína bruta (CPB); ganho de peso (GP), eficiência de utilização da PB (EUPB) e conversão alimentar (CA) de novilhas mestiças confinadas

Table 6 - Average daily intake of dry matter (DMI), organic matter (OMI), neutral detergent fiber (NDFI), acid detergent fiber (ADFI), crude protein (CPI); average daily gain (ADG), ADG:CPI ratio and feed:gain ratio of feedlot crossbred heifers

\begin{tabular}{|c|c|c|c|c|c|}
\hline \multirow[t]{2}{*}{$\begin{array}{l}\text { Item } \\
\text { Item }\end{array}$} & \multicolumn{4}{|c|}{$\begin{array}{c}\text { Níveis de substituição (\%) } \\
\text { Replacement levels (\%) }\end{array}$} & \multirow[t]{2}{*}{$\begin{array}{l}\text { Equações de regressão } \\
\text { Regression equations }\end{array}$} \\
\hline & 0 & 20 & 40 & 60 & \\
\hline $\begin{array}{l}\text { CMS (kg/dia) } \\
D M I \text { (kg/day) }\end{array}$ & 5,95 & 6,82 & 6,19 & 6,13 & $Y=6,27$ \\
\hline $\begin{array}{l}\text { CMS (\% PV) } \\
D M I(\% L W)\end{array}$ & 2,88 & 3,14 & 2,98 & 2,92 & $\mathrm{Y}=2,98$ \\
\hline $\begin{array}{l}\text { CMO (kg/dia) } \\
\text { OMI (kg/day) }\end{array}$ & 5,65 & 6,34 & 5,70 & 5,69 & $\mathrm{Y}=2,78$ \\
\hline $\begin{array}{l}\text { CMO }(\% \mathrm{PV}) \\
O M I(\% L W)\end{array}$ & 2,73 & 2,92 & 2,74 & 2,71 & $\mathrm{Y}=2,78$ \\
\hline $\begin{array}{l}\text { CFDN (kg/dia) } \\
N D F I \text { (kg/day) }\end{array}$ & 2,31 & 2,66 & 2,41 & 2,39 & $\mathrm{Y}=2,44$ \\
\hline $\begin{array}{l}\text { CFDN (\%PV) } \\
N D F I(\% L W)\end{array}$ & 1,12 & 1,22 & 1,16 & 1,14 & $Y=1,16$ \\
\hline $\begin{array}{l}\text { CFDA (kg/dia) } \\
A D F I \text { (kg/day) }\end{array}$ & 1,31 & 1,49 & 1,41 & 1,37 & $\mathrm{Y}=1,39$ \\
\hline $\begin{array}{l}\text { CFDA (\%PV) } \\
A D F I(\% L W)\end{array}$ & 0,63 & 0,69 & 0,68 & 0,65 & $Y=0,66$ \\
\hline $\begin{array}{l}\text { CPB (kg/dia) } \\
\text { CPI (kg/day) }\end{array}$ & 0,80 & 0,91 & 0,84 & 0,83 & $\mathrm{Y}=0,85$ \\
\hline $\begin{array}{l}\text { EUPB }(\mathrm{kg} \mathrm{GP} / \mathrm{CP}) \\
A D G: C P I \text { ratio }\end{array}$ & 1,44 & 1,48 & 1,40 & 1,41 & $Y=1,43$ \\
\hline $\begin{array}{l}\mathrm{CA}(\mathrm{kg} \mathrm{MS} / \mathrm{kg} \mathrm{GP}) \\
D M I: A D G \text { ratio }\end{array}$ & 5,17 & 5,18 & 5,33 & 5,23 & $Y=5,23$ \\
\hline $\begin{array}{l}\text { GP kg/dia) } \\
A D G(k g / \text { day })\end{array}$ & 1,15 & 1,35 & 1,16 & 1,17 & $Y=1,21$ \\
\hline
\end{tabular}


Experimento 2. Os resultados referentes ao ganho de peso em $\mathrm{kg} / \mathrm{dia}$ (GP), conversão alimentar (CA), eficiência de utilização da proteína bruta (EUPB) e as consumos de matéria seca (MS), matéria orgânica (MO), fibra em detergente neutro (FDN), fibra em detergente ácido (FDA) e proteína bruta (PB), em função dos níveis de substituição do farelo de soja pela mistura milho + uréia, são apresentados na Tabela 6.

Como pode ser verificado, não houve efeito $(\mathrm{P}>0,05)$ da substituição do farelo de soja por milho mais uréia sobre o consumo de MS nas três formas expressas, embora haja uma tendência de comportamento quadrático. Níveis elevados de nitrogênionão-proteico, poderiam induzir a toxidez, pelo excesso de liberação de amônia, reduzindo o consumo. Por outro lado, Church (1974) cita que a ingestão de alimentos poderá ser reduzida devido ao sabor amargo da uréia, quando fornecida em grande quantidade. No presente trabalho esta ausência de significância foi devida, provavelmente, ao fornecimento da dieta na forma de ração completa, a palma forrageira apresenta alta palatabilidade e os níveis de substituição ficaram limitados até 38\% do nitrogênio total da dieta.

Kozloski et al. (1997) e Seixas et al. (1997), também não verificaram diferença no consumo de MS em bovinos confinados, ao substituírem, respectivamente, farelo de algodão e farelo de soja pela uréia.

Com relação aos consumos de $\mathrm{MO}, \mathrm{PB}, \mathrm{FDN}$, e FDA, também não foi verificada influência da substituição do farelo de soja por milho mais uréia. Este fato pode ser explicado por não ter havido diferença no consumo de MS e as rações terem apresentado níveis similares desses nutrientes (Tabela 2) e o fator limitante da ingestão de alimentos, provavelmente, não ter sido o enchimento.

Como pode ser verificado, não houve efeito $(\mathrm{P}>0,05)$ da substituição sobre o ganho de peso, conversão alimentar e eficiência de utilização da proteína refletindo o comportamento verificado para o consumo de nutrientes.

Resultados semelhantes foram verificados por Seixas et al. (1997), ao compararem o farelo de algodão e uréia como fonte de proteína para bovinos cruzados em confinamento. Da mesma forma Silva et al. (1997b) recomendaram o uso de uréia como fonte exclusiva de nitrogênio na ração de novilhos Nelore em confinamento.

Segundo Campos \& Lizieire (1998) o ganho de peso excessivo de novilhas na fase prépubertal, pode acarretar redução na futura produção de leite, devido ao crescimento alométrico da glândula mamária. Os ganhos observados podem ser considerados altos, já que os recomendados para novilhas de raças grandes estão entre 0,8 e $0,9 \mathrm{~kg} / \mathrm{dia}$. Por outro lado, Van Amburgh et al. (1998) não verificaram quedas na produção de leite de novilhas holandesas na primeira lactação, superalimentadas ou não.

Também não foi verificado efeito $(\mathrm{P}>0,05) \mathrm{da}$ substituição do farelo de soja por milho mais uréia quanto à conversão alimentar, observando-se conversão média de $5,2 \mathrm{~kg}$ de MS consumida/ $\mathrm{kg}$ de ganho de peso. Estes resultados diferem dos observados por Seixas et al. (1997) que verificaram conversão média de 8,$41 ; 8,01$; e 7,67, respectivamente, para farelo de algodão, uréia e amiréia. Coutinho Filho (1993) trabalhando com bovinos em confinamento, e dietas compostas de cana de açúcar e farelo de algodão ou uréia, obteve conversões de 10,3 e 11,3 kgMS/kgGP. Estas variações observadas são atribuídas às diversas variáveis nos experimentos, como idade dos animais, período experimental, raça, sexo e rações avaliadas. As melhores médias observadas neste experimento podem ser atribuídas a grande quantidade de palma forrageira na dieta, uma vez que a mesma é rica em carboidratos-nãofibrosos (Wanderley, 2001), uma fonte de energia prontamente assimilável para os ruminantes (Van Soest, 1994) e apresentar comportamento semelhante a concentrados, quanto à digestibilidade dos nutrientes (Ferreira et al., 2001).

O desempenho semelhante dos animais pode ser atribuído à forma de fornecimento da ração, e ao fato de a palma apresentar em sua composição, altos teores de carboidratos solúveis, proporcionando aos microrganismos ruminais energia suficiente para síntese de proteína microbiana (Silva et al., 1997a).

Alguns trabalhos demonstraram a importância da palma forrageira na dieta de vacas de leite (Mattos, 2000 e Wanderley, 2001). Os dois experimentos anteriormente discutidos comprovam a viabilidade de sua utilização como alimento base na dieta de bovinos de leite em crescimento. As principais deficiências dessa cactácea, nitrogênio e fibra, podem ser minimizadas, com a inclusão na dieta de alimentos de baixo custo e de fácil aquisição na região como o bagaço de cana e uréia. O baixo teor de matéria seca da palma forrageira também tem sido apontado como fator limitante. Porém, em regiões semi-áridas deveria ser considerado como um fator positivo por solu- 
cionar o problema de falta de água para os animais.

Vale ressaltar que os desempenhos diferentes obtidos nos dois ensaios podem ter sido devidos, tanto aos ingredientes, quanto aos nutrientes contidos nas dietas experimentais. No experimento I, na medida em que aumentou a participação do bagaço de cana houve redução nas proporções de palma forrageira. Além disso, o concentrado utilizado foi o farelo de trigo, que refletiram teores de PB nas dietas de 11,3; 11,2 e $11,1 \%$, respectivamente, para os níveis de 5,5; 14,4 e $24,4 \%$ de bagaço de cana.

Por outro lado, no Experimento II, a palma forrageira e o bagaço de cana contribuíram igualmente com 50 e $30 \%$ em todas as rações experimentais, respectivamente, mas os ingredientes utilizados nos concentrados foram milho moído, farelo de soja e uréia; caracterizando portanto, uma ração com perfil de nutrientes melhor balanceado.

\section{Conclusões}

A adição de bagaço de cana aumenta o consumo de matéria seca, porém o ganho de peso é diminuído. A decisão pelo nível de bagaço a ser utilizado deverá respeitar o desempenho desejado e o aspecto econômico.

A mistura milho mais uréia pode substituir o farelo de soja em até $60 \%$ em dietas à base de palma forrageira para novilhas mestiças.

\section{Literatura Citada}

ARAÚJO, G.G.L.; SILVA, J.F.C.; VALADARES FILHO, S.C. et al. Consumo e digestibilidade total dos nutrientes de dietas contendo diferentes níveis de volumoso, em bezerros. Revista Brasileira de Zootecnia, v.27, n.2, p.345-354, 1998.

BARTLE, S.J.; PRESTON, R.L.; MILLER, M.F. Dietary energy sources and density: effects of roughage equivalent, talow level, and steer type on feedlot performance and carcass characteristics. Journal of Animal Science, v.72, n.8, p.1943-1953, 1994.

CAMPOS, O.F.; LIZIEIRE, R.S. Estratégias para obtenção de fêmeas de reposição em rebanhos leiteiros. In: PEIXOTO, A.M.; MOURA, J.C.; FARIA, V.P. (Eds.) Planejamento da exploração leiteira. Piracicaba: Fundação de Estudos Agrários Luiz de Queiroz, 1998. p.215-226.

CARVALHO, A.U.; VALADARES FILHO, S.C.; SILVA, J.F.C., et al.. Níveis de concentrado em dietas de zebuínos.1.Consumo e digestibilidade aparente. Revista Brasileira de Zootecnia, v.26, n.5, p.986-995, 1997.

CHURCH, D.C. Gusto, apetito e regulacion de la ingesta de alimentos; In: CHURCH, D. C. (Ed.) Fisiologia digestiva y nutricion de los ruminantes. Zaragoza: Acribia, 1974. p.405-435.

COUTINHO FILHO, J.L.V. Estudo de rações compostas por diferentes fontes de nitrogênio através do desem- penho e digestibilidade aparente com ruminantes. Jaboticabal: Universidade Estadual Paulista, 1993. 69p. Dissertação (Mestrado em Zootecnia) - Universidade Estadual Paulista, 1993.

FERREIRA, M.A. Desempenho, exigências nutricionais e eficiência de utilização da energia metabolizável para ganho de peso de bovinos F1 Simental x Nelore. Viçosa, MG: Universidade Federal de Viçosa, 1997. 97p. Tese (Doutorado em Zootecnia) - Universidade Federal de Viçosa, 1997.

FERREIRA, M.A.; ANDRADE, D.K.B.; VERAS, A.S.C. et al. Associação da palma forrageira (Opuntia fícus-indica Mill)e silagem de sorgo (Sorgun bicolor): Digestibilidade aparente “1”. In: REUNIÃO ANUAL DA SOCIEDADE BRASILEIRA DE ZOOTECNIA, 38., 2001, Piracicaba.Anais...Piracicaba: Sociedade Brasileira de Zootecnia, 2001. p.1127-1128.

KOZLOSKI, G.V.; RIBEIRO FILHO, H.M.N.; ROCHA J.B.T. et al. Efeito da uréia sobre a digestão do amido em novilhos.In: REUNIÃO ANUAL DA SOCIEDADE BRASILEIRA DE ZOOTECNIA, 34., 1997, Juiz de Fora.Anais... Juiz de Fora: Sociedade Brasileira de Zootecnia, 1997. p.435-437.

MATTOS, L.M.E. Associação da palma forrageira (Opuntia ficus indica Mill) com diferentes fontes de fibra na alimentação de vacas mestiças em lactação. Recife: Universidade Federal Rural de Pernambuco, 1996. 51p. Dissertação (Mestrado em Zootecnia) - Universidade Federal Rural de Pernambuco, 2000.

MERTENS, D.R. Análise da fibra e sua utilização na avaliação de alimentos e formulações de rações. In: SIMPÓSIO INTERNACIONAL DE RUMINANTES, 1992, Lavras, Anais... Lavras: Sociedade Brasileira de Zootecnia, 1992. p.188-211.

NUSSIO, L.G.; BALSALOBRE, M.A.A. Utilização de resíduos fibrosos da industrialização da cana de açúcar na alimentação de bovinos. In: SIMPÓSIO SOBRE NUTRIÇÃO DE BOVINOS, 1993, Piracicaba. Anais... Piracicaba: Fundação de Estudos Agrários Luiz de Queiroz, 1993. p.127-149.

OLIVEIRA F.R. Alternativas de alimentação para a pecuária no semi-árido nordestino. In: SIMPÓSIO NORDESTINO DE ALIMENTAÇÃO DE RUMINANTES, 6., 1996, Natal. Anais. . Natal: SNPA, 1996. p.127-197.

SANTANA, O. P., VIANA, S. P., ESTIMA, A. L. et al. Palma versus silagem na alimentação de vacas leiteiras. Revista Brasileira de Zootecnia, v. 1, n. 1, p. 31-40, 1972.

SANTOS, D.C.; FARIAS, I.; LIRA, M.de A.et al. A palma forrageira (Opuntia ficus indica Mill e Nopalea cochenillifera Salm-Dyck) em Pernambuco: cultivo e utilização. Recife: IPA, 1997. 23p. (Documentos, 25).

SEIXAS, J.R.C.; EZEQUIEL, J.M.B.; MARTINS JUNIOR, A.P. et al. Desempenho de bovinos confinados recebendo amiréia, uréia ou farelo de algodão. In: REUNIÃO ANUAL DA SOCIEDADE BRASILEIRA DE ZOOTECNIA, 34., 1997, Juiz de Fora. Anais... Juiz de Fora: Sociedade Brasileira de Zootecnia, 1997. p.295-297.

SIGNORETTI, R.D.; SILVA, J.F.C.; VALADARES FILHO, S.C. et al. Crescimento, conversão alimentar e rendimento de carcaça de bezerros da raça holandesa alimentados com dietas contendo diferentes níveis de volumoso. Revista Brasileira de Zootecnia, v.28, n.1, p.185-194, 1999a.

SIGNORETTI, R.D.; SILVA, J.F.C.; VALADARES FILHO, S.C. et al. Consumo e digestibilidade aparente em bezerros da raça holandesa alimentados com dietas contendo diferentes níveis de volumoso. Revista Brasileira de Zootecnia, v.28, n.1, p.169-177, 1999b. 
SILVA, D.J. Análise de alimentos (métodos químicos e biológicos). Viçosa, MG: Universidade Federal de Viçosa, 1990. $165 \mathrm{p}$.

SILVA, M.F.; BATISTA, A.M.V.; ALMEIDA, O.C. Efeito da adição de capim elefante a dietas à base de palma forrageira sobre a fermentação ruminal em bovinos. In: REUNIÃO ANUAL DA SOCIEDADE BRASILEIRA DE ZOOTECNIA, 38., 1997a, Juiz de Fora. Anais... Juiz de Fora: Sociedade Brasileira de Zootecnia, 1997a. p.140-142..

SILVA, J.M.; FEIJÓ, G.L.D.; PORTO, J.C.A, et al. Efeito de fontes de nitrogênio e do tipo de silagem no desempenho de novilhos nelore. In: REUNIÃO ANUAL DA SOCIEDADE BRASILEIRA DE ZOOTECNIA, 34. 1997b. Juiz de Fora. Anais...Juiz de Fora: Sociedade Brasileira de Zootecnia, 1997b. p. 286-288.

TIBO, G.C.; VALADARES FILHO, S.C.; SILVA, J.F.C., et al.. Consumo, digestibilidade e metodologia de coleta de amostras de digesta em novilhos alimentados com vários níveis de concentrado. In: REUNIÃO ANUAL DA SOCIEDADE BRASILEIRA DE ZOOTENIA, 34., 1997, Juiz de Fora. Anais... Juiz de Fora: Sociedade Brasileira de Zootecnia, 1997. p.234-236.
VAN AMBURGH, M.E.; GALTON, D.M.; BAUMAN, D.E. et al. Effects of three prepurtal body growth rates on performance of holstein heifers during first lactation. Journal of Dairy Science, v.81, n.2, p. 527-538, 1998.

VAN SOEST, P. J. Nutrional ecology of the ruminant. 2. ed. New York: Cornell University Press, 1994. 476 p.

WANDERLEY, W.L. Palma forrageira (Opuntia ficus indica Mill) em substituição à silagem de sorgo (Sorghum bicolor (L.) Moench na ração de vacas holandesas em lactação. Recife: Universidade Federal Rural de Pernambuco, 1996. 41p. Dissertação (Mestrado em Zootecnia) Universidade Federal Rural de Pernambuco, 2001.

WEISS, W.P. Estimating the available energy content of feeds for dairy cattle. Journal of Dairy Science, vol.81, n.3, p.830-839, 1998.

Recebido em: 03/03/02

Aceito em: 06/11/02 